\title{
Green jobs, social dialogue and participatory governance for sustainable water policy reforms
}

\author{
C. R. Carrión-Crespo \\ International Labour Office, Switzerland
}

\begin{abstract}
The International Labour Organization (ILO) has developed several activities related to water supply. Among them, the search for ways to transition to a green economy has received much attention. The ILO has also identified the lack of social dialogue within the water utility services as one of the main obstacles to the reforms in water supply around the world. This latter challenge is an important component in the search for better governance which should lead to more efficient and available service. This is because joint, bottom-up planning and implementation of reforms by governments, employers and workers will result in stronger support within the sector and more sustainable reforms. This can be achieved through information sharing, consultation, participation, negotiations and other mechanisms to foster understanding between diverse interests.

In order to promote social dialogue, the ILO recommends that labour and employer associations be independent, strong and well-informed. Governments should show the will to recognize and consult with these organizations, and develop mechanisms that work both in law and in practice. For this purpose, the ILO has pursued an Action Programme in Perú, Malawi, Nigeria, and the Philippines. The Action Programme seeks to strengthen social dialogue in the utilities in these countries by establishing steering groups, researching the problems of the sector in each country, and supporting the development of national plans of action.
\end{abstract}

Keywords: international labour office, green jobs, social dialogue, sustainable development, governance. 


\section{Introduction}

The International Labour Organization (ILO) was founded in 1919 as part of the Versailles peace agreements, in an attempt to avoid future wars through the establishment of common standards that would protect people from a race to the bottom. It is also the only UN agency to include a tripartite Structure, which provides governments, workers and employers participation in its governing structures. It survived the Second World War and in 1946, it became the first UN agency. It has adopted 189 international conventions addressing different aspect of the working life, the latest being the Convention on Domestic Workers adopted in 2011. The ILO received the 1969 Nobel Peace Prize in recognition for its first 50 years of continuous activity and its social activism, as illustrated by its 1964 denunciation of apartheid. Presently, the ILO promotes labour standards, employment creation, social protection and social dialogue as crucial elements of the campaign for decent work. As part of this effort, The ILO joined the network of UN agencies that work with water issues, called UN-Water, in February 2010.

Access to water is a human right that must be ensured through participative governance, not only through technology and engineering. Access to water is becoming a crucial issue in world affairs, and soon may be more important than oil. The main challenge to ensuring access to water has been guaranteeing that the water is safe and does not force people to devote precious time and resources to obtaining it. Children and women have borne most of the effort. The water community acknowledges that privatization efforts have not overcome the challenges, and in many cases, like Paris, have been rolled back.

The tripartite approach and the ILO's expertise in pursuing decent work add value to the international community's effort. The ILO emphasizes the social aspects of water supply: increased and better employment, stakeholder participation in reform processes, and an integrated approach to ecological concerns. The ILO's activities on water focus on Green Jobs,

One of the approaches that the ILO takes to advance its agenda is to develop sectoral activities. This is a specialized approach to workplace issues in an integral manner in each economic sector. This way, the ILO advances a "vertical" integration of knowledge and provides continuous contact with actors in all aspects of each sector. The ILO has identified 22 economic sectors, among them utilities (Water, electricity and gas).

\section{Green jobs}

The promotion of Green Jobs is central in the transition towards a greener economy and poverty eradication. The ILO, The UN Environment Programme (UNEP), the International Trade Union Confederation (ITUC) and the International Organization of Employers (IOE) established the Green Jobs Initiative to promote opportunity, equity and just transitions and to mobilize governments, employers and workers to engage in dialogue regarding coherent policies and effective programmes in over 20 developing and emerging 
countries. These policies can help avoid job losses, create employment and promote sustainable development. The ILO, UNEP, IOE and ITUC [1] published the first comprehensive study on the emergence of a "green economy" and its impact on the world of work. It includes data that shows a changing pattern of employment in which green jobs are being generated in many sectors and economies as a result of measures to tackle climate change and to reduce emissions of greenhouse gases. It found that the policy frameworks in place at the time generated a fraction of their potential benefits for jobs and development. An updated report due this fall will include country assessments for potential Green Jobs through a sectoral analysis.

The ILO [2] also examined how 21 developed and developing countries have provided training to meet the new demands of a greener economy. It shows that skills shortages hinder the potential to unlock the employment potential of green growth. The report recommends that countries devise strategies based on wellinformed policy decisions, social dialogue, and coordination among ministries and between employers and training providers.

\section{Social protection and decent work}

One of the major challenges to achieve both economic growth and development in all countries is promoting decent work - employment, social protection, social dialogue and rights at work. Stable incomes and decent employment support sustainable development. The current economic crisis has shown the need for sound social protection policies to sustain livelihoods and lessen long-term economic and social scarring which result from market disruptions. Social transfers alone cannot support long term development: we also need policies that create opportunities for productive employment and decent work for all. Relevant reports and country experiences show that a transition to a green economy can lead to net gains in employment and particularly benefit the poor, youth and women.

The transition to a green economy may also include down-sides. Some sectors will see slower growth or a loss of employment, particularly in industrialized countries with a strong brown economy. For these situations, a just transition is needed for enterprises, workers and communities including access to social protection, to new skills and to alternative employment and income opportunities (ILO [3]). Social dialogue is a critically important component of a just transition at regional, national and sectoral levels as well as in the workplace, where the voice of workers can help design new sustainable production systems and work practices. Employers' and workers organizations, especially from communities most affected by the transition, can generate the social acceptance needed to make a shift at the scale and speed required. This engagement rests on the foundations of international labour standards especially on freedom of association and the promotion of mechanisms for social dialogue.

UNEP [4] demonstrates that green investments contribute to reduce environmental damage while boosting economic growth and creating jobs. The ILO has found a need for skilled workers, qualified employers and informed and 
engaged labour market institutions and the importance of social dialogue as an essential tool for successful transformation. Investing in a green economy can produce growth, create jobs and contribute to development and poverty reduction.

The ILO [5] has also assisted in developing local infrastructure and public works that help communities adapt to climate change by supporting: i) water and land resource management in rural areas, ii) Flood control, drainage and water conservation structures, iii) Rural transport improvement and maintenance.

\section{Empowerment of marginalized people}

Green Jobs can also promote inclusive economic development. Organized waste pickers, for example, contribute to the waste management system of cities and enterprises, while they (i) improve working conditions, (ii) multiply incomes, (iii) promote gender equity, (iv) reduce child labour and (v) promote sustainable livelihoods for adults. Successful examples are found in all continents, like Brazil, Argentina, India, Sri Lanka and Tanzania in Africa. Green economy policies should promote greater gender equity and mitigate damage done to Indigenous people by deforestation, erosion, and water scarcity, due to their close relation to nature. The ILO's Convention No. 169 on Indigenous and Tribal Peoples is fundamental to assure negative impacts are identified in advance and measures to minimize them are implemented.

It is not necessary to choose between the environment on the one hand and employment and growth on the other. Both aims will be achieved by investing in green, clean and sustainable sectors, creating decent work opportunities for all and supporting the creation of sustainable enterprises.

\section{Current issues in water utilities}

In 2003, governments, employer and worker representatives met in the ILO headquarters in Geneva to discuss the challenges and opportunities facing the public utilities They identified the restructuring of public utilities, deregulation, liberalization and privatization as trends. Also, they agreed that the industry had witnessed the following phenomena:

- Increasing participation of multinational enterprises

- Job cuts and reduced wages

- Health, safety and training often marginalized in the water sector

- Workers are subject to poor conditions in dangerous environments

- Lack of information

- Insufficient involvement of workers and local enterprises

- Poor governance

- Little clarity concerning transfers and job security

- $\quad$ Scarce capacity building and training 
The participants concluded that training for lifelong learning and to improve efficiency can improve productivity and customer service, and that technological developments may improve the quality and quantity of services and working conditions, like reducing strenuous tasks and offering opportunities for women. However, they require careful planning and joint consultation, in view of the potential impact on jobs, conditions of employment, work organization, training needs, etc. They identified social dialogue as the best way to address these issues. Social dialogue helps develop joint strategies to improve utility services, to extend access to services to all communities, improve efficiency of delivery and review tariffs and other sources of income collection

It is very important to establishing political support in order to facilitate the resolution of water management issues and promote change, investment and sound management arrangements: "Determining what will change and how involves political bargaining and stakeholder negotiation." (Global Water Partnership [6]). Governments are learning that improvement in arrangements for the administration of water resources offer one of the least costly ways to resolve water management problems in a timely manner (Young [7]).

Social Dialogue intends to foster the understanding between diverse interests on issues of common interest relating to economic and social policy. It includes information sharing, consultation, participation, negotiations and collective bargaining. The ILO's Declaration on Social Justice for a Fair Globalization (2008) asserted that "Social dialogue and tripartism [are] the most appropriate methods for ... translating economic development into social progress, and social progress into economic development; [and] facilitating consensus building on relevant national and international policies that impact on employment and decent work strategies and programmes"

Social dialogue seeks to build consensus and prevent conflict. It can exist as a tripartite process, with the government as an official party to the dialogue or it may consist of bipartite relations only between labour and management (or trade unions and employers' organizations), with or without indirect government involvement. It can be informal or institutionalised, or a combination of the two. It can be organized at national, regional or enterprise level, as well as at the interprofessional or sectoral levels or a combination thereof.

The ILO has identified the following prerequisites for an effective social dialogue:

- Independent, representative and strong social partners enjoying Freedom of Association in law and in practice

- Will to recognise and deal with each other

- Political will of the government to reach out to social partners and support them in the effort

- Effective Social Dialogue institutions

- Effective rules and procedures

- $\quad$ Practice and experience 
The conclusions of the Tripartite Meeting on Challenges \& Opportunities Facing Public Utilities encouraged constituents to respect and defend the right of workers, employers and their representatives to timely information and consultation; ensure that the provision of public services respect and promote the fundamental principles and rights at work; and promote good employment practices like the retention and separation of workers through training, proper social security and redeployment mechanisms for workers.

\section{Action programme to strengthen social dialogue in the utilities}

In 2008, the ILO began this action programme with the objectives of helping governments and labour and employer organizations to develop joint strategies and actions to extend and improve the efficiency of the fundamental public utility services; helping identify policy solutions; and improve national and local processes of social dialogue. The strategy followed was to establish country steering mechanisms, decide on research priorities \& baseline indicators, perform baseline studies, develop national activities like workshops and seminars, facilitate the design of national and local plans of action, and mobilizing resources from donors. The Social dialogue model consists of four phases: Planning, Initiating, Implementing, and Monitoring and Evaluating. The following figure illustrates the activities:

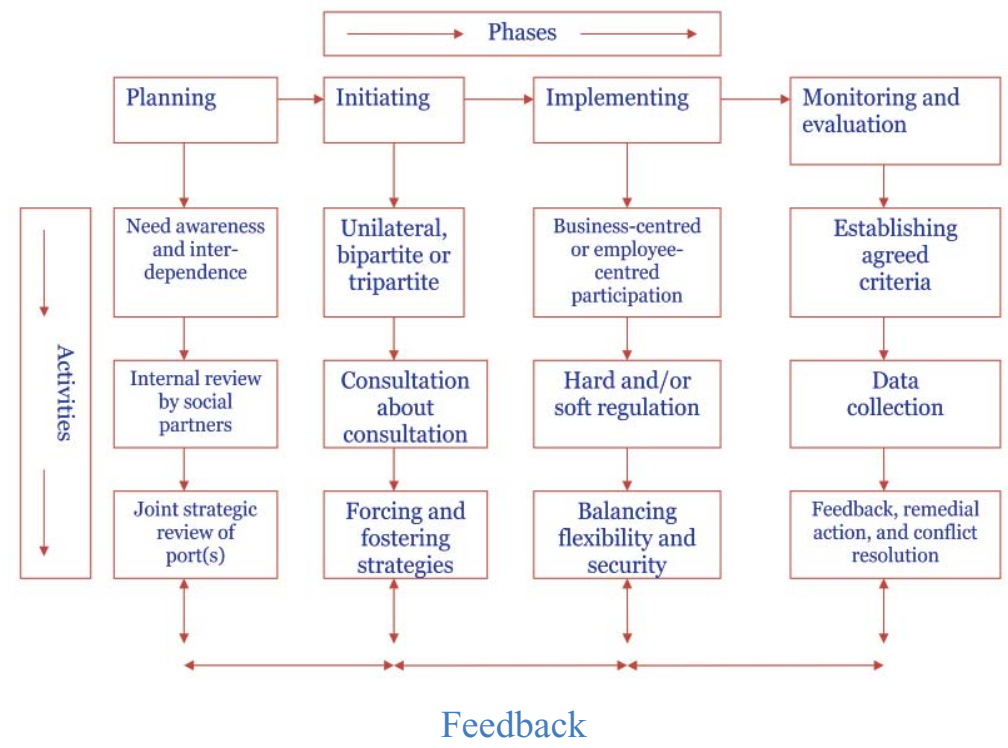

Figure 1: $\quad$ Phases and activities of social dialogue. Source: Turnbull [8, p. 81]. 
The programme seeks to add value to national reform programmes in the following ways:

- Involving workers, employers and their representatives in planning reforms strengthens process.

- Workers and water supply enterprises know the operations and often are closer to users.

- Unions and employer associations help build confidence, provide transparency and overcome resistance, which helps ensure sustainability and provide key support.

The theory of organizational change behind this programme follows (Turnbull [8]). Effective organizational change happens when there is consensus building and a conscious effort to empower employees coupled with the institution of cultural change through a bottom-up approach, in contrast to topdown impositions from the management. Organizational development entails the entire process of transforming organizations that deliver water, by "revitalizing and renewing" their "technical and human resources". It is the process rather than the result of the efforts or attempts to improve an organization's effectiveness in delivering a particular service.

The following are characteristics of organizational development that should be emphasized during the reform process:

- It should focus on the whole organization, not through a piece-meal approach

- It should take an "open systems" approach, which means that it does not deny the influence of the political and economic systems on the organization

- It should use problem-solving and group process approaches, meaning decisions should be taken after consulting groups and with a bottom-up approach

- It should rely heavily on feedback to participants, to promote a continuing flow of information

- It should provide experiential learning for participants to accomplish their aims, to allow improvement through experience

- It should be situational and contingency based, assuming that there is no one-size-fits-all strategy but needs to adjust to specific situations

- It should use outside experts or "change agents" to facilitate changeacknowledges that there is no monopoly of solving problems and allows facilitators to recognize what needs to be changed and how to do it.

There are three processes in which organizational change can happen. The directive is usually directed from the top-down and tends to result in changing only the behaviour of employees because they tend to follow the management because of its coercive capacity. The second is process reengineering, which aims to transform how the different components of the organization interact with each other. This is referred to as side-to-side change because it allows employees 
to see how their work affects other employees. Hence, it results in both attitudinal and behavioural change. The third and the best process of organizational change is empowerment which is undertaken from the bottom-up by empowering employee through consensus-building and participatory approach. This is likely to change the culture of the organisation, not only the behaviour and the attitudes of its employees. The following figure illustrates this:

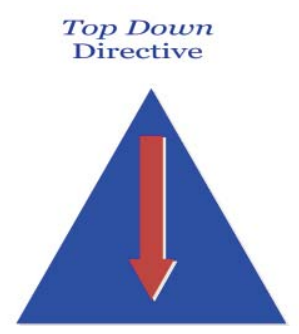

Figure 2: $\quad$ Forms of organizational change initiatives.

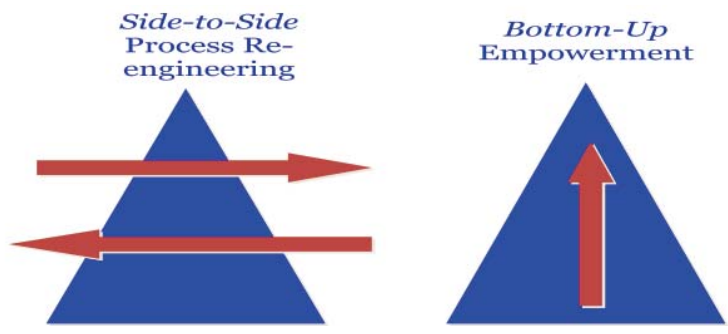

To underscore the essence of the third and the best form of organizational change, Schein [9] provides a definition of organizational culture: "the pattern of basic assumptions that a given group has invented, discovered or developed, in learning to cope with its problems of external adaptation and internal integration. These have worked well enough to be considered valid and are therefore taught to new members as the correct way to perceive, think and feel in relation to these problems."

Legge [10] suggested a strategy to approach organizational cultures: "Managing culture can be likened to 'riding a wave' - the best a surfer can do is understand the pattern of currents and winds that shape and direct the waves, then use these to stay afloat and steer the desired path. Clearly, this is not the same as changing the basic rhythms of the ocean." Essentially, this means that lasting organizational change can happen if the organization identifies the forces that move its employees to act; if employees are involved and consulted in identifying and resolving the problems of the organizations, the chances to institute successful reforms are improved.

Nonetheless, many times efforts to change organizations fail because:

- It is not integrated to a strategy

- It is seen as a "fad" or "quick fix"

- A short-term perspective

- Political realities undermine initiatives

- Programmes create unrealistic expectations

- Inflexible strategy or policies

- Absence of leadership

- Lack of measurable or tangible results 
- Fear of the unknown

- It is unable to mobilize commitment to sustain change

To make change happen, therefore, it is necessary to:

- Have leaders committed to the change

- Create a feeling of shared need among all members

- Shape a vision that will move the change

- Mobilize commitment to the process

- Modify systems and structures that may impede the change

- Monitor the progress of the change

Make change last through investment by members of the organization

The ILO has identified social dialogue as the key to achieving the bottomsup, integrated approach to organizational change. To make it effective, the social partners may follow the following steps:

- Identify the right problem.

- Analyze the problem.

- Identify decision criteria.

- Develop multiple solutions.

- Choose the optimal solution.

- Prepare for contingencies.

The action programme seeks to strengthen the social partners' ability to achieve this, through capacity-building and facilitation exercises. The success of the ILO's action programme will be measured according to the following indicators:

- $\quad$ The social partners (employer and worker organizations) have developed mechanisms/capacity to engage in social dialogue;

- Selected utilities companies at municipal level have implemented a modernisation plan with the full and active participation of the union and workforce;

- The results of achieved service delivery improvements of utility companies shared systematically with other ministries, and with the range of utility operators in order to integrate them into the national MDG activities;

- National governments have best practice examples for replication in other countries or sectors.

The programme has resulted in the following activities at present:

- Malawi- A proposal for social dialogue mechanism made by workers and will be discussed in nation's cabinet, with employer support. 
- Nigeria- Labour Advisory Council will function as tripartite social dialogue forum, focusing on strengthening labour inspection to build trust in the utilities sector, through a technical committee.

- Peru- A facilitator is currently assisting the creation of municipal and central social dialogue fora, and a technical secretariat to support them.

- Philippines- A training of trainers on social dialogue was held in June 2011, and currently the participants are providing training to their colleagues. An Executive Order will be drafted in November 2011 and presented to the Office of the President.

Therefore, we can say that the action programme is progressing towards satisfactory completion. A self-evaluation exercise performed in 2010-11 by the ILO [11] concluded the following:

- The number of activities developed met the expectations established by the Governing Body of the ILO at the outset.

- The Action Programme is a relevant tool for the ILO to implement its work on the ground.

- Indications of the level of satisfaction of the intended beneficiaries are generally encouraging.

- A two-year timescale is very short to create and nurture contacts in countries, and that a better balance is needed between the time and resources spent in designing APs and the actual AP implementation.

- Mandates of multi-regional coverage were difficult to achieve and did not provide tangible advantages.

These activities face serious challenges. We need to build capacity in dialogue principles and skills, prioritise social dialogue in reform strategies, and to obtain funding to ensure sustainability. The political will needs to be fostered thorough continuity in the efforts of national governments. Expectations tend to be very high after each activity and it requires resources to match them. Also, we need to ensure that institutional memories are preserved to ensure continuity. And we need to ensure that activities are carried out despite unstable political circumstances.

\section{Conclusion}

The ILO has developed a series of activities which seek to strengthen the ability of member states to confront the challenges facing water supply around the world. Through these efforts, the ILO joins other UN agencies in a united front. The future of these activities depends on the strength of the partnerships developed. 


\section{References}

[1] ILO et al., Green Jobs Report (2008), http://www.ilo.org/wcmsp5 /groups/public/---ed_emp/---emp_ent/documents/publication/wcms_158733 .pdf

[2] ILO, "Skills for Green Jobs: A global view" (2010), http://www.ilo.org/wcmsp5/groups/public/@ed_emp/@ifp_skills/document s/publication/wcms_156220.pdf

[3] ILO, "Social Security for Social Justice and a Fair Globalization," http://www.ilo.org/wcmsp5/groups/public/---ed norm/--relconf/documents/meetingdocument/wcms_152819.pdf

[4] UNEP, Green Economy Report (2010), http://www.unep.org/ greeneconomy/GreenEconomyReport/tabid/29846/ Default.aspx

[5] ILO, "Local investments for climate change adaptation: in brief-- Green jobs through green works," http://www.ilo.org/wcmsp5/groups/public/--asia/---ro-bangkok/documents/publication/wcms 155743.pdf.

[6] Global Water Partnership, Policy Brief 8: Triggering change in water policies, 2009, p.6. http://www.indiaenvironmentportal.org.in/files/GWP Policy_brief8_English.pdf.

[7] Young, M. "Water: Investing in natural capital," p. 30, in ILO et al., Green Economy Report, citing the background paper "The Effectiveness of Alternative Water Governance Arrangements," by C Menard and R M Saleth. Menard's and Saleth's paper will be published as Chapter 8 of M Young and C Esau (Eds.), Investing in Water for a Green Economy: Services, Infrastructure, Policies and Management, (Routledge, February 2012).

[8] Turnbull, P. Social dialogue in the process of structural adjustment and private sector participation in ports: A practical guidance manual (ILO, 2005).

[9] Schein, E. H. Organizational Culture and Leadership (Jossey-Bass, 1985), p. 18.

[10] Legge, K. Human Resource Management: Rhetoric and Realities (Macmillan, London, 1995).

[11] ILO, Evaluation of the action programmes on health services, public services, telecommunication services and utilities, GB.310/STM/5, p. 2, http://www.ilo.org/wcmsp5/groups/public/---ed_norm/---relconf/ documents/meetingdocument/wcms_150807.pdf 